\title{
Healthcare disparities in thoracic malignancies
}

Thanks to the pandemic and the concurrent social unrest, healthcare disparities in the United States has finally become a prioritized topic of discussion and a need for action $(1,2)$. Race, ethnicity, socioeconomic status, education status, immigrant status, primary language, place of work, access to care, and housing in racially segregated neighborhoods all factor in the inequity of care. For example residential segregation significantly impacts the mortality rates of Blacks from benign diseases including hypertension, or cardiovascular disease (3), as well as the treatment for and outcomes of patients with solid tumors (4-7). Disparities exist in every phase of oncological care ranging from screening to diagnosis to delivery of treatment $(8,9)$. Multiple studies have demonstrated potential causes for healthcare disparities in particular between Blacks and Whites $(10,11)$. Proposed and established root causes of these disparities include biologic differences (12-14), access to healthcare, lack of insurance (14), socioeconomic factors (14,15), health literacy (16), and perception of the stigma of cancer (14). Some of the important steps in mitigating these disparities is to investigate the details of the causes and to raise awareness in the populations at risk. We invited clinicians and surgeons with their boots on the ground in this arena to provide current reviews of the literature on healthcare disparities in the management and treatment of those with thoracic malignancies. As follows we also will share some of our thoughts on the topic.

One of the important observations we have made is that when studying disparity, it is imperative to study these issues in the pertinent population. With regards to lung cancer screening, the National Lung Screening Trial investigators demonstrated the efficacy of CT screening, however with only $4.5 \%$ of study participation Blacks were severely under-represented (17). While that study set forth the lung cancer screening criteria ( $>$ age 55; pack year $>30$ ), we do not know how applicable the criteria are to Blacks, Indigenous people and other people of color. The Southern Community Cohort Study investigated $\sim 85,000$ non-screened adults of whom 67\% were Black and found that Blacks develop lung cancer with lower smoke exposure (median pack year 26) than Caucasians (pack year 48) (18). To corroborate this suspicion, the same study showed that only $17 \%$ of Blacks compared with $31 \%$ of Whites meet current screening criteria. This racial disparity remained true among those who developed lung cancer-only $32 \%$ of Blacks compared with $56 \%$ of Whites who retrospectively met screening criteria were diagnosed with cancer (18). Working at a major safety-net hospital where Blacks represent $~ 35 \%$ of the patient population, we have shown that Blacks are less likely to be screened even when they meet the current USPSTF criteria (19). This evidence suggests that Blacks are at greater risk for lung cancer but less likely to be screened. Studies focusing on such vulnerable populations is necessary to bring a better understanding to this topic.

Disparity in screening in part explains why the vulnerable population would present at later stages. However, even when stage-matched, disparities persist in the delivery of treatment as well as the outcomes. In this issue Evans et al. review the role of disparity in the treatment of early-stage lung cancer patients and demonstrate that lower socioeconomic status is associated with a higher incidence of lung cancer, lower utilization of surgery and poorer outcomes after surgery (20). Lin et al. reviewing the role of disparities and stereotactic body radiotherapy (SBRT) for early stage lung cancer, demonstrate that patients with lower income, education, and socioeconomic origins were less likely to receive SBRT when indicated and more likely to receive conventionally fractionated external beam radiation or no treatment (21). For advanced lung cancers Stein et al. review differences in palliative care, mutation analysis and immunotherapy in particular (22).

With regards to other solid tumors, Delman et al. review the role of disparity in esophageal cancer and apply the conceptual framework of Torain et al.: patient, provider, system/access, clinical care/quality, and postoperative outcomes, to provide a straightforward approach to dissecting the issues and formulating specific interventions $(23,24)$. Freudenberger et al. review the role of disparity in the diagnosis, treatment, and prognosis of malignant pleural mesothelioma, and Singh et al. provide an overview of disparities in extra-thoracic solid tumors $(25,26)$. To address the issue of gender, Baiu et al. review the role of sex in the diagnosis, treatment and prognosis of women with lung or esophagus cancer (27).

In reviewing health disparities in thoracic malignancies, we can draw the following conclusions. Firstly, this is a pervasive societal problem and although the turbulence of 2020, got the ball rolling we cannot lose the momentum to address the injustice. Secondly, the complex nature of the issue mandates a move beyond the large databases to more investigations with granular details of the patients involved- capturing frailty indices, cultural concerns, social support. With this approach we 
may move toward formulation of clear actionable items. The conceptual framework in the Delman et al. piece allows us to formulate focused interventions ranging from local community engagement efforts to policy changes at the system level. One example of community-level efforts is a geocode analysis at the local level using patient addresses, to identify specific communities needing more help. Thirdly, a combined effort may be in order to investigate this issue as a group, perhaps in the form of a consortium of safety-net hospitals (SNH). While no consensus exists on the definition of SNH (28), SNH in general provides healthcare for individuals regardless of their insurance status or ability to pay and thus play a major role in serving these vulnerable populations. Such combined efforts would lead to better representation of these populations in future studies, and more importantly, a better effort to study potential interventions to mitigate the disparities.

\section{Acknowledgments}

Funding: None.

\section{Footnote}

Provenance and Peer Review: This article was commissioned by the editorial office, Journal of Thoracic Disease, for the series "Socioeconomic Disparities in the Treatment of Thoracic Malignancies". The article did not undergo external peer review.

Conflicts of Interest: Both authors have completed the ICMJE uniform disclosure form (available at http://dx.doi.org/10.21037/ jtd-2021-15). The series "Socioeconomic Disparities in the Treatment of Thoracic Malignancies" was commissioned by the editorial office without any funding or sponsorship. Dr. VRL and Dr. SK served as the unpaid Guest Editors of the series. Dr. VRL received Honorarium from UPMC Esophageal course 12/2020: "pyloroplasty" and "ERAS" talks, and she served as treasurer of Thoracic Surgery Foundation. The authors have no other conflicts of interest to declare.

Ethical Statement: The authors are accountable for all aspects of the work in ensuring that questions related to the accuracy or integrity of any part of the work are appropriately investigated and resolved.

Open Access Statement: This is an Open Access article distributed in accordance with the Creative Commons AttributionNonCommercial-NoDerivs 4.0 International License (CC BY-NC-ND 4.0), which permits the non-commercial replication and distribution of the article with the strict proviso that no changes or edits are made and the original work is properly cited (including links to both the formal publication through the relevant DOI and the license). See: https://creativecommons.org/ licenses/by-nc-nd/4.0/.

\section{References}

1. Siegel RL, Miller KD, Jemal A. Cancer statistics, 2018. CA Cancer J Clin 2018;68:7-30.

2. Siegel RL, Miller KD, Jemal A. Cancer statistics, 2019. CA Cancer J Clin 2019;69:7-34.

3. Landrine H, Corral I. Separate and unequal: Residential segregation and black health disparities. Ethn Dis 2009;19:179-84.

4. Blanco BA, Poulson M, Kenzik KM, et al. The Impact of Residential Segregation on Pancreatic Cancer Diagnosis, Treatment, and Mortality. Ann Surg Oncol 2021;28:3147-55.

5. Poulson M, Cornell E, Madiedo A, et al. The Impact of Racial Residential Segregation on Colorectal Cancer Outcomes and Treatment. Ann Surg 2021;273:1023-30.

6. Poulson MR, Beaulieu-Jones BR, Kenzik KM, et al. Residential Racial Segregation and Disparities in Breast Cancer Presentation, Treatment, and Survival. Ann Surg 2021;273:3-9.

7. Poulson MR, Helrich SA, Kenzik KM, et al. The impact of racial residential segregation on prostate cancer diagnosis and treatment. BJU Int 2021;127:636-44.

8. Balekian AA, Wisnivesky JP, Gould MK. Surgical Disparities Among Patients With Stage I Lung Cancer in the National Lung Screening Trial. Chest 2019;155:44-52. 
9. Sabatino SA, White MC, Thompson TD, et al. Cancer screening test use - United States, 2013. MMWR Morb Mortal Wkly Rep 2015;64:464-8.

10. Haas JS, Earle CC, Orav JE, et al. Racial segregation and disparities in cancer stage for seniors. J Gen Intern Med 2008;23:699-705.

11. Mandelblatt J, Andrews H, Kao R, et al. Impact of access and social context on breast cancer stage at diagnosis. J Health Care Poor Underserved 1995;6:342-51.

12. Heath EI, Lynce F, Xiu J, et al. Racial Disparities in the Molecular Landscape of Cancer. Anticancer Res 2018;38:2235-40.

13. Hede K. Drilling Down to the causes of racial disparities in lung cancer. J Natl Cancer Inst 2010;102:1385-7.

14. Lannin DR, Mathews HF, Mitchell J, et al. Influence of socioeconomic and cultural factors on racial differences in late-stage presentation of breast cancer. JAMA 1998;279:1801-7.

15. Mandelblatt J, Andrews H, Kerner J, et al. Determinants of late stage diagnosis of breast and cervical cancer: the impact of age, race, social class, and hospital type. Am J Public Health 1991;81:646-9.

16. Bennett CL, Ferreira MR, Davis TC, et al. Relation between literacy, race, and stage of presentation among low-income patients with prostate cancer. J Clin Oncol 1998;16:3101-4.

17. National Lung Screening Trial Research Team. Reduced lung-cancer mortality with low-dose computed tomographic screening. N Engl J Med 2011;365:395-409.

18. Aldrich MC, Mercaldo SF, Sandler KL, et al. Evaluation of USPSTF Lung Cancer Screening Guidelines Among African American Adult Smokers. JAMA Oncol 2019;5:1318-24.

19. Steiling K, Loui T, Asokan S, et al. Age, Race, and Income are Associated with Lower Screening Rates at a Safety Net Hospital. Ann Thorac Surg 2020;109:1544-50.

20. Evans N 3rd, Grenda T, Alvarez NH, et al. Narrative review of socioeconomic and racial disparities in the treatment of early stage lung cancer. J Thorac Dis 2021;13:3758-63.

21. Lin Y, Mak KS. Racial and Socioecononomic Racial and socioeconomic disparities in the use of stereotactic body radiotherapy for treating non-small cell lung cancer: a narrative review. J Thorac Dis 2021;13:3764-71.

22. Stein K, Rivera MP, Weiner A, et al. Sociodemographic Disparities in the Management of Advanced Lung Cancer: A Narrative Review. J Thorac Dis 2021;13:3772-800.

23. Delman AM, Ammann AM, Turner KM, et al. A narrative review of socioeconomic disparities in the treatment of esophageal cancer. J Thorac Dis 2021;13:3801-8.

24. Torain MJ, Maragh-Bass AC, Dankwa-Mullen I, et al. Surgical Disparities: A Comprehensive Review and New Conceptual Framework. J Am Coll Surg 2016;223:408-18.

25. Freudenberger DC, Shah RD. A narrative review of the health disparities associated with malignant pleural mesothelioma. J Thorac Dis 2021;13:3809-15.

26. Singh S and Sridhar P. A narrative review of sociodemographic risk and disparities in screening, diagnosis, treatment, and outcomes of the most common extrathoracic malignancies in the United States. J Thorac Dis 2021;13:3827-43.

27. Baiu I, Titan AL, Martin LW, et al. The role of gender in non-small cell lung cancer: a narrative review. J Thorac Dis 2021;13:3816-26.

28. Popescu I, Fingar KR, Cutler E, et al. Comparison of 3 Safety-Net Hospital Definitions and Association With Hospital Characteristics. JAMA Network Open 2019;2:e198577. 


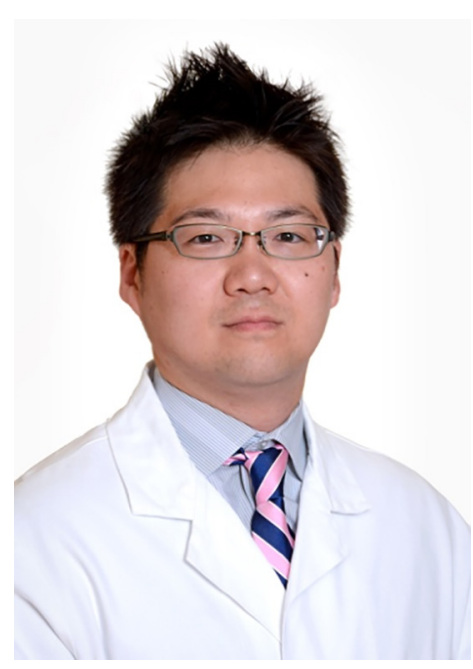

Kei Suzuki

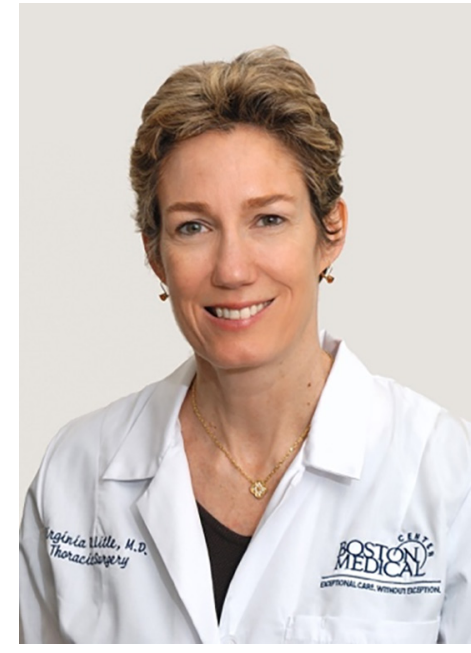

Virginia R. Litle

Kei Suzuki (Email: kei.suzuki@bmc.org) Virginia R. Litle

(Email: Virginia.litle@bmc.org) Division of Thoracic Surgery, Department of Surgery, Boston University School of Medicine, Boston, MA, USA. Submitted Mar 08, 2021. Accepted for publication Mar 19, 2021. doi: $10.21037 /$ jtd-2021-15

View this article at: http://dx.doi.org/10.21037/jtd-2021-15

Cite this article as: Suzuki K, Litle VR. Healthcare disparities in thoracic malignancies. J Thorac Dis 2021;13(6):3741-3744. doi: $10.21037 /$ jtd-2021-15 